\title{
The Research on the Integration of Patriotism Education and Research Travel in the Elementary and Middle Schools of Central Region of Guangxi
}

\author{
Li Ruiyun 1, a, Wei Huanhuan 1, b, ,Liu Wan 2, c, ,Fang Jiajue ${ }^{3, \text { d, * }}$ \\ ${ }^{1}$ School of Culture and Communication of Guangxi Science \& Technology Normal University; Laibin, Guangxi, China \\ 546199 \\ ${ }^{2}$ Guangxi Science \& Technology Normal University Library; Laibin, Guangxi, China 546199 \\ ${ }^{3}$ Teaching Quality Monitoring and Evaluation Office of Guangxi Science \& Technology Normal University; Laibin, \\ Guangxi, China 546199 \\ 1937116147@qq.com \\ b2767180995@qq.com \\ c80137570@qq.com \\ 'Jiayu10000@163.com
}

\begin{abstract}
Modern education is undergoing unprecedented changes in the new era. It undertakes the great mission of cultivating scientific literacy and humanistic literacy. Comparing with the traditional and unitary teaching model in the past, the experiential research study, which centers on tourism + has an important impact on the implementation of the task of fostering people and promoting the reform of quality education. Therefore, the state has identified researching travel as an important supplementary form of school education, and promoted it vigorously. Among them, the organic integration of patriotism and research travel is a highlight of research travel. It plays vital role for strengthening patriotism education and cultivating patriotism among primary and middle school students. Based on the current situation in centre region of Guangxi, this article sets forth from the four aspects: research camp, teacher training, safety management, and after-class evaluation, to clarify its development relationship, and to explore new ways of integration, so as to promote the efficient and organic integration of research travel and patriotism, promote the sound development of research travel, fulfill the task of fostering talents, and finally realize quality education.
\end{abstract}

Keywords: the central region of Guangxi, elementary and middle schools, patriotism, research travel, integration

\section{桂中中小学爱国主义教育与研学旅行融合的路径研究}

\author{
李瑞云 ${ }^{1, a}$, 韦欢欢 ${ }^{1, b}$, 刘万 ${ }^{2, c}$, 方家珏 ${ }^{3, d * *}$
}

1 广西科技师范学院文化与传播学院; 来宾, 广西, 中国 546199

2 广西科技师范学院图书馆; 来宾, 广西, 中国 546199

3 广西科技师范学院教学质量监控与评估处; 来宾, 广西, 中国 546199

1937116147@qq.com

b2767180995@qq.com

c80137570@qq.com

dJiayu10000@163.com 
摘要: 进入新时代, 现代教育正在发生前所未有之大变, 承担着培养科学素养和人文素养的伟大使命, 与过 去学校课堂传统的、单一的教育模式相比, 推进以 “旅游+” 为主的体验式研学旅行发展对于落实立德树人任 务, 促进素质教育改革有重要影响。为此, 国家将研学旅行确定为学校教育重要补充形式, 大力推进研学旅行 发展, 其中, 爱国主义与研学旅行有机融合是研学旅行的一大亮点, 对于加强爱国主义教育, 培养中小学生的 爱国主义情感有重要作用。本文基于桂中地区的现状, 从研学基（营）地，导师培养，安全管理，以及课后评 价四方面进行论述, 理清发展关系, 探讨融合新方式, 促进研学旅行与爱国主义高效有机融合, 推动研学旅行 良性发展，实现立德树人任务，发展素质教育。

关键词: 桂中地区; 中小学; 爱国主义; 研学旅行; 融合

\section{1.前言}

青年一代有理想, 有本领, 有担当, 国家就有前 途, 民族就有希望, 实现中华民族伟大复兴的中国梦， 离不开一代代青年的接力奋斗。[1]国家历来重视对中 小学生开展爱国主义教育, 培养爱国情怀。进入新时 期, 面对百年未有之大变局, 机遇与挑战并存, 过去 学校课堂传统重知识轻实践的爱国主义教育单一模 式已经落后是社会发展足迹, 无法满足中小学生日益 增长对于知识的需求, 在实现民族复兴的关键时期, 教育部等11部门颁布了《关于推进中小学研学旅行的 意见》 (以下简称《意见》), 为中小学爱国主义教育 开展和时代新人培养提供方式, 是爱国主义与研学旅 行实现深度融合的理论指导, 分析并厘清《意见》中 关于研学基 (营) 地, 导师培养, 安全管理, 以及课 后评价等相关内容, 是实现新时代中小学生爱国主义 研学旅行融合开展, 提升效果, 进而实现爱国主义教 育的关键。

\section{2.当前桂中地区研学旅行的现状}

《意见》的出台, 标志着中国研学旅行已然从星 星之火发展成燎原之势, 首次将研学旅行纳入中小学 课程体系, 明确研学旅行地位, 作为学校教育和校外 教育衔接的创新形式, 成为中小学教育的刚需, 中国 研学旅行迈进发展新时期。《研学旅行服务规范》详 细规定研学旅行开展各个环节的要求; 《中小学德育 工作指南》强调把研学旅行纳入学校教育教学计划;

《教育部基础教育司 2018 年工作要点》指出要推进 研学实践教育营地和基地建设; 《研学旅行基地（营 地）实施与服务规范》规范和提升研学旅行基地（营 地）服务质量, 这些政策从不同方面为研学旅行保驾 护航, 赋予研学旅行更多教育价值, 促进研学旅行快 速发展, 使之成为落实树德立人根本任务的重要载体。 其中, “研学旅行+”的教育模式备受关注, 研学旅行 + 教育、研学旅行 + 工业、研学旅行+博物馆等研学旅行 模式遍地开花, 实现学科知识的跨界融合, 研学旅行 取得长足发展。
位于广西桂中地区的柳州来宾抓住国家发展研 学旅行的机遇, 促使桂中地区的研学旅行从无到有, 再到拥有国家级基地和省级研学营地, 研学旅行课程 涉及广西全域, 实现了校内教育与校外教育的有效衔 接, 满足桂中地区中小学生开展研学旅行需求。但大 好形势之下也有一些不尽人意之处, 研学旅行基地建 设不规范, 研学导师人才缺乏, 安全保障淡薄, 课程 评价形式化等问题, 制约研学旅行有效开展, 限制着 研学旅行教育功能的发挥。

\section{3.爱国主义与研学旅行的融合作用}

爱国主义与研学旅行实践教育高效有机融合, 以 爱国主义为内涵, 研学旅行为形式, 发挥研学旅行实 践教育作用, 弥补传统课堂重知识轻实践爱国主义教 育的缺陷, 构建完备的中小学爱国主义教育体系, 爱 国主义教育达到知识与实践相结合, 推动落实树德立 人根本任务实现。通过实践教育, 更能加深爱国主义 内涵的了解, 弘扬爱国主义, 培养爱国情怀, 进而在 实践中将爱国情怀转化为报国行动, 书写人生新篇, 树立报国志向，成为社会主义核心价值观的积极践行 者, 传统文化的传承者, 社会主义的接班人, 为实现 中华民族伟大复兴接力奋斗。

\section{1 发挥实践活动对爱国主义的培养作用}

读万卷书, 行万里路。爱国主义教育不能仅依靠 传统课堂讲授式培养, 需要发挥多种形式的教育, 重 视实践教育在培养人的功用, 创新教育模式。实践作 为教育方式之一, 对中小学爱国主义教育有着不可替 代的作用。《意见》明确指出中小学研学旅行是学校 教育与校外教育衔接的创新形式, 是教育教学的重要 内容, 是综合实践育人的有效途径。[2]实践是研学旅 行一大特性, 与当下爱国主义教育需求有着天然的契 合度。成为了爱国主义教育的重要载体。中共中央国 务院印发的《新时代爱国主义教育实施纲要》（以下 简称《纲要》) 恰逢其时, 《纲要》要求把青少年作 为爱国主义教育的重中之重, 将爱国主义精神贯穿于 学校教育全过程, 注重创新爱国主义教育的形式, 广 泛组织开展实践活动, 丰富拓展爱国主义教育校外实 
践领域。建好用好爱国主义教育基地和国防教育基地, 强化爱国主义教育和红色教育功能, 为社会各界群众 参观学习提供更好服务。强调要依托自然人文景观和 重大工程开展教育, 寓爱国主义教育于游览观光之中, 引导人们领略壮美河山, 投身美丽中国建设。[3]这些 要求明确爱国主义主义教育的内容, 指明了开展爱国 主义教育的方式, 肯定了实践教育活动对于爱国主义 培养的作用。通过开展爱国主义研学旅行, 进行实践 教育活动, 学生走出课本, 用双脚丈量祖国大好河山, 用双眼领略历史的波澜壮阔, 用双手触摸社会的巨大 变革, 增进祖国的了解, 从而让学生知道新中国来之 不易, 中国特色社会主义来之不易, 深刻认识到中国 共产党为什么能, 马克思主义为什么行。中国特色社 会主义为什么好。激发学生对党、对国家、对人民的 热爱之情, 树立起正确的爱国观, 增强做中国人的志 气。

\section{2 发挥实践活动对爱国主义的转化作用}

少年强, 则国强。爱国主义不仅需要在实践中培 养, 更需要在实践中转化, 将中小学生的爱国主义情 怀转化为中小学爱国主义行动是实践教育的初心和 使命。研学旅行是一种以实践为主的新型教育教学方 式, 为将青少年的爱国主义转化为爱国、报国实际行 动提供新路径。在抗战遗址, 名人故居开展革命研学 旅行, 广泛开展党史、国史教育, 感受革命光荣历史; 走进历史文化遗迹、博物馆, 进行传统文化研学旅行, 传承和弘扬中华优秀传统文化, 感受中华传统美德; 依托教育基地、重大工程, 参与改革开放研学旅行, 深入开展中国特色社会主义和中国梦教育, 感受改革 开放的伟大成就。用新民主主义时期取得的革命成果 说话, 用中华五千年沉淀的优秀传统文化发声, 用改 革开放以来创造的举世成就证明。在润物细无声中滋 养青少年的爱国主义, 在潜移默化中转变为青少年的 强国报国行动, 确保爱国主义教育成果可见、爱国主 义教育行动可观。在实践中引导青少年在伟大事业实 践中发挥先锋作用、激荡青春力量, 从而展现青春新 气象、彰显青春新活力、创造青春新作为。[4]

\section{4.桂中地区爱国主义与研学旅行融合的有效 建议}

爱国主义与研学旅行相互贯通, 以研学旅行作为 载体, 囊获爱国主义内涵, 实现二者深度融合, 发挥 实践教育作用, 对于中小学生爱国主义教育有着深刻 影响力。与时俱进地创新了中小学爱国主义教育的内 涵建设与实施方法, 切实促进我国中小学爱国主义教 育的长效发展。 ${ }^{[5]}$ 基于研学旅行开展环境的开放性, 教育内容的复杂性, 参与主义的多元性。爱国主义研 学旅行在实际开展中存在一些不足, 影响着教育效果 的发挥, 需要对爱国主义研学旅行进行探讨, 本文从 基（营）地建设、导师培养、安全管理以及有效评价 四个方面提出策略。

\section{1 基（营）地建设是爱国主义与研学旅行融 合的基础}

实践的特性决定爱国主义研学旅行开展需要必 须有场所支撑, 在研学旅行中, 研学基地或研学营地 是实施研学教育活动的重要载体, 是实现研学实践教 育目的的重要依托, 是完成研学实践活动的重要保证。 ${ }^{[6]}$ 重视和完善基地的建设, 是实现爱国主义与研学旅 行融合的基础。从 2017 年到 2018 年, 连续两年教育 部公布了研学实践教育基地与营地名单, 其中, 广西 共有 17 个基（营）地，爱国主义基（营）地就有 7 个, 为开展研学旅行提供了充足的场所保障; 《教育 部基础教育司 2018 年工作要点》指出要推进研学实 践教育营地和基地建设, 为研学旅行基地和研学营地 建设提供政策支持; 《研学旅行基地（营地）设施与 服务规范》提出提升研学旅行基地 (营地)服务质量, 为研学基地和研学营地的管理提供规范。《意见》把 加强研学旅行基地建设作为主要任务之一。明确提出 要根据研学旅行育人目标, 结合域情、校情、生情, 依托自然和文化遗产资源、红色教育资源和综合实践 基地，大型公共设施、知名院校、工矿企业、科研机 构等, 遴选建设一批安全适宜的中小学研学旅行基地。 [7]从政策上提供基（营）地建设的依据和保障，明确 基（营）地的目的, 肯定了研学基（营）地是开展研 学旅行的重要一环。

桂中地区历史文化底蕴深厚, 有着悠久的革命历 史和丰富爱国主义教育资源, 是爱国主义教育中不可 替代的教材, 为建设和全面开展爱国主义研学旅行提 供了得天独厚的资源条件。借助昆仑关战役遗址建设 以抗战为主的爱国主义实践教育基地，依托柳州市工 业博物馆建设以科技强国为主的爱国主义实践教育 基地, 通过来宾市和柳州市博物馆建设以继承和弘扬 传统文化和民族文化为主的爱国主义实践教育基地。 打造一批示范性好、布局合理、互联互通的爱国主义 实践教育基地群, 作为开展爱国主义研学旅行的重要 依托, 实现资源整合共享, 开发一批示范性爱国主义 实践教育精品课程和路线, 作为革命传统教育、科技 强国教育、传统文化教育的重要载体。

\section{2 研学导师培养是爱国主义与研学旅行融合 的关键}

人才是引领行业发展的第一资源, 实现爱国主义 研学旅行良性发展, 需从人才培养入手, 发挥研学导 师的核心作用。研学导师是学生参与研学旅行实实践 教育的引领者, 在整个研学过程中承担着言传身教的 光荣职责。[8]在当下, 研学旅行已经纳入中小学教育 教学计划, 参加研学旅行成为了中小学生教育刚需, 研学导师的需求进一步凸显。

研学旅行作为横跨教育与旅游两个领域的新型 融合行业, 无论是旅游行业的导游还是教育领域的教 师都无法自给自足, 做到独立完成研学旅行课程研发 
与实行。因此, 整合社会资源, 借助多方力量, 自上 而下和自下而上双向出发培养符合新时代研学旅行 发展的复合型人才成为关键。导游或教师通过培训, 快速弥补短板, 实现能力增长, 成为胜任研学导师的 优秀人才，2019年10月“研学旅行管理与服务”正式 列入《普通高等学校高等职业教育(专科)专业目录》 2019年增补专业。[9]将研学旅行发展人才培养提上日 程, 更是从源头解决研学导师不足、不专的弊端式。 借助高校培养人才的强大能力和现代学徒制培养优 势，通过校企合作，共建教育基地，实现人才培养的 深度融合, 培养一批培养具有品德高尚、耐心细致的 职业气质, 具备现代教育理念和较高人文素养, 熟悉 中小学生教育教学规律, 掌握旅游学科基础知识和团 队服务技巧, 能够从事研学线路开发、研学课程设计 与实施以及相关研学指导工作的复合型高技能人才。 [10]弥补当下研学导师市场的空缺。同时, 作为当下研 学旅行行业主要从业者, 传统旅行社、研学机构、学 校应重视人才的培养和能力的提升, 做好研学导师培 养, 制定研学导师培训体系, 规范不当行为, 提升职 业能力, 引导研学导师对自身能力提升的需要和重视, 促进行业健康发展, 满足市场对高素质研学导师人才 的强烈需求。

\section{3 安全管理是爱国主义与研学旅行融合的保 障}

安全是实践教育的出发点和落脚点, 研学旅行坚 持教育为本、安全第一的原则。尽管目前研学旅行实 践中发生的安全事故只是少数, 但随着研学旅行规模 的不断扩大, 潜在的安全风险势必加大。[11]研学旅行 的安全管理也会随之成为关注的焦点和令人担忧的 痛点, 提高安全管理意识, 重视安全管理, 是研学旅 行与爱国主义融合的保障。

爱国主义研学旅行是培养中小学生爱国主义情 怀, 增强文化自信和国家认同感, 树立维护国家安全 理念, 实现树德立人根本任务。服务的对象有很大的 特殊性, 需要在研学旅行安全管理上出大力, 打重拳。 坚持从思想到行为规范, 再到制度保障全方位落实安 全管理。《意见》以贯彻党的十八大和十八届三中、 四中、五中、六中全会精神, 深入学习贯彻习近平总 书记系列重要讲话精神为指导思想。[12] 研学旅行的 主办方、承办方要以文件精神为指导思想, 加强安全 管理思想意识教育, 守住安全管理底线, 牢牢树立生 命至上的安全观, 坚持做到知行合一和学以致用, 制 定科学有效研学旅行安全保障方案, 将对安全管理的 认识转化为实际行动, 将安全管理做到落实落细, 自 觉自为, 政府部门更要加强监督管理, 完善研学旅行 安全管理机制, 落实安全责任主体, 制定研学旅行安 全工作标准体系, 明确安全工作标准, 建立安全问题 分类标准, 确保安全管理问题导向。[13]从而形成完整 的研学旅行安全管理体系。

\section{4 有效评价是爱国主义与研学旅行融合的反 馈}

作为一门课程, 研学旅行应做到活动前要有设计, 活动中要有探究, 活动后要有评价。[14]有效评价是对 爱国主义研学旅行教育效果的评价, 是对爱国主义与 研学旅行融合的反馈, 也是对进一步发展和提升积累 经验和数据。

《意见》指出各地要建立健全中小学生参加研学 旅行的评价机制 ${ }^{[15]}$, 爱国主义研学旅行作为一种特殊 的教育方式, 既有一般课程的共性, 也有自身的特殊 性, 研学旅行评价标准体系建立需要树立辩证思维, 运用具体问题具体分析方法论, 从多方入手。第一结 合多方力量共建评价体系, 研学旅行是由学校基地研 学旅行机构等多方主体共同参与, 协作完成, 相应地, 作为课程一部分的评价标准体系也应由各方共同搭 建。第二评价方式要多样性, 学生自评, 小组互评, 老师点评, 家长联评, 整合各方意见形成最终评价; 第三评价内容要多元化, 根据学段和内容的形式而有 侧重点, 重视对学生在课程实施过程中的表现, 通过 采取小学阶段提示方式、初中阶段交流方式、高中阶 段研讨方式, 进行区分考核。[16]第四评价突出实践性, 研学旅行强调将所学知识, 掌握技能应用到实践中, 实现育人目的, 评价要起到引导作用, 启发学生学思 并重, 侧重学生在教育过程中的表现, 能力上的收获 以及学习成果在行动上的表现, 达到知行合一, 学以 致用。

\section{5.结论}

爱国主义是中小学生立德树人根本任务的核心 内容, 也是评判立德树人根本任务能否有效实现的重 要指标。将爱国主义与研学旅行相结合, 借助研学旅 行实践教育的优势, 以爱国主义为内核, 以研学旅行 的形式, 弥补课堂教育缺失, 最终达到知行合一的效 果, 培养出社会所需要的人才。本文通过基（营）地 建设、导师培养、安全管理以及有效评价四个方面对 爱国主义与研学旅行相融合进行论述, 并对存在的问 题进行探讨, 为爱国主义与研学旅行进一步融合提出 本文建议, 以期使中小学生立德树人根本任务在爱国 主义研学旅行中顺利实现。

\section{项目基金}

本文为 2020 年国家级大学生创新训练计 划项目《桂中中小学爱国主义研学旅行的研究 与实践》（项目编号 202011546009）的阶段性 研究成果之一。

\section{REFERENCES}

[1] Xi Jinping wrote back to encourage Chinese students from Moscow University to carry forward 
the glorious tradition of studying abroad and serving the country, so that the light of youth shines on the road to struggle for their dreams [EB/OL].:(2017-12-30) [2021-2-04] http://www.xinhuanet.com/politics/2017-12/30/c_1 122190240.htm

[2] 11 departments including the Ministry of Education. Opinions on the promotion of research trips for elementary and middle school students [EB/OL].: (2016-12-19) [2021-2-04] http://www.gov.cn/xinwen/2016-12/19/content_51 49947.htm

[3] "Outline for the Implementation of Patriotic Education in the New Era" issued by the Central Committee of the Communist Party of China and the State Council [EB/OL].: (2019-11-12) [2021-2-04] http://www.gov.cn/zhengce/2019-11/12/content_54 51352.htm

[4] Xi Jinping. Decisively win over a well-off society in an all-round way and win the great victory of socialism with Chinese characteristics in the new era-a report at the 19th National Congress of the Communist Party of China 2017-10-12 [M]. Beijing: People's Publishing House, 2017.

[5] Bai Yunhua. Several important regulations on patriotism education for young people in the new era_analysis based on the "Outline for the Implementation of Patriotism Education in the New Era" [j].The Party Building and Ideological Education in Schools,2019(19):42-46.

[6] Guo Xiaoying. Patriotism Education in the Study Trip of Elementary and Secondary Schools in the New Era [J].Moral Education China,2020(03):30-40.

[7] Ye Yali, Bian Xiying. [M].Research and study travel base (camp) service and management. Beijing: Tourism Education Press,2020:3.

[8] 11 departments including the Ministry of Education. Opinions on the promotion of research trips for elementary and middle school students[EB/OL].: (2016-12-19) [2021-2-04] http://www.gov.cn/xinwen/2016-12/19/content_51 49947.htm

[9] Deng Dezhi, Wu Xin. Practice of research travel instructor[M] .Beijing: Tourism Education Press , 2020:16-18

[10] The Ministry of Education announced the "Professional Catalogue of Higher Vocational Education (Specialty) in General Colleges and Universities" to add majors in 2019[EB/OL].:
(2019-10-18) [2021-2-04]

http://www.moe.gov.cn/s78/A07/zcs_ztzl/2017_zt 06/17zt06_bznr/bznr_ptgxgdzjml/ptgx_mlxjzydz/2 01910/t20191018_404286.html

[11] Sun Lei.Exploration and Analysis of Talent Training of Higher Vocational Research Tutors under the Background of Research Travel [J].Journal of Wuxi Institute of Technology,2020,19(03):7-10.

[12] Zhang Mingchuan, Gou Ronghua.Types, causes and prevention of safety accidents in research travel [J]. Journal of Teaching and Management, 2020 (22) :16-18.

[13] 11 departments including the Ministry of Education. Opinions on the promotion of research trips for elementary and middle school students [EB/OL].: (2016-12-19) [2021-2-04] http://www.gov.cn/xinwen/2016-12/19/content_51 49947.htm.

[14] Wu Junsheng. China Research Travel Safety Development Report Blue Book (2017-2019) [M]. Shandong: Shandong Education Press,2020:38-41.

[15] Yu Shujuan, Wang Yuan, Wu Huijun.我国研学 Causes and countermeasures of travel problems [J]. Journal of Teaching and Management,2017(19):11-13

[16] 11 departments including the Ministry of Education. Opinions on the promotion of research trips for elementary and middle school students [EB/OL].: (2016-12-19) [2021-2-04] http://www.gov.cn/xinwen/2016-12/19/content_51 49947.htm.

[17] Shen Hejiang, Gao Haisheng, Li Zhiyong. Research trip: evaluation of essential attributes, constituent elements and effects $[\mathrm{J}]$. Tourism Tribune, 2020,35(09):10-11 